\title{
Development of in-situ observation system of dynamic contact interface between dies and materials during microforming operation
}

\author{
Tetsuhide Shimizu ${ }^{\mathrm{a}}$, Tai Kakegawa, and Ming Yang \\ Division of Intelligent Mechanical Systems, Tokyo Metropolitan University, 6-6 Asahigaoka Hinoshi, \\ 191-0065 Tokyo, Japan
}

\begin{abstract}
Application of diamond like carbon (DLC) films are reported in several microforming processes, in view of its great tribological performance owe to the low friction and the high chemical stability. However, due to its high internal residual stress, the film properties with the low adhesion strength and the high wear rate under severe tribological conditions are still remain as technical issues. However, since the dynamic variation of the contact state cannot be observed during the forming operation, it is difficult to recognize the origin and the influential tribological factors of tool life for DLC coated microforming die. Therefore, the appropriate DLC film properties for the contact state in microforming operation have not been clarified. To observe the dynamic variation of the contact state during the microforming operation, present study developed a novel microforming die assembly installed the in-situ observation system with silica glass die and high speed recording camera. By using this system, the dynamic delamination behaviour of DLC films during the progressive micro-bending process was successfully demonstrated. The influential factors for the durability of DLC coated microdies were discussed.
\end{abstract}

\section{Introduction}

In view of the remarkable increase of surface area to volume ratio with miniaturization of the process dimension in microforming, the tribological properties become more dominant for the forming process. Additionally, within the background of the requirement for lubricant-free forming [1], the activities applying the hard film coatings on microforming dies are gradually increasing [2]. In particular, the application of diamond like carbon (DLC) films are reported in several microforming processes, in view of its great tribological performance owe to the low friction and the high chemical stability. [3]. First application was reported by Yang et al., who applied to the micro-extrusion die using pulse plasma chemical vapor deposition (CVD) method [4]. Similarly, the friction properties of DLC coated microdies were followed by Krishnan et al., for micro-extrusion process [5] and by Fujimoto et al. for microbending process [6], Aizawa et al. for micro-bending with ironing [7], and $\mathrm{Hu}$ et al. [8] and by Wang et al. [9] for micro-deep drawing process.

\footnotetext{
${ }^{a}$ Corresponding author: simizu-tetuhide@tmu.ac.jp
}

This is an Open Access article distributed under the terms of the Creative Commons Attribution License 4.0, which permits unrestricted use, distribution, and reproduction in any medium, provided the original work is properly cited. 


\section{MATEC Web of Conferences}

In spite of these developments, the problems in low adhesion strength of DLC films with substrate has been remained as a technical challenges to endure under the high impact surface pressure in forming process [10]. However, since the dynamic variation of the contact state cannot be observed during the forming operation, it is difficult to recognize the origin and the influential tribological factors of tool life for DLC coated microforming die. Particularly in progressive forming process, since the contact state varies at each number of processes, it becomes further difficult to trail the history from the origin of delamination of DLC itself. For these reasons, the appropriate DLC film properties for the contact state in microforming operation have not been well discussed. To observe the dynamic variation of these contact states during the actual microforming operation, present study developed a novel microforming die assembly installed the in-situ observation system with silica glass die and high speed recording camera. By using this system, the dynamic delamination behaviour of DLC films during the progressive micro-bending process was observed. The influential factors for the durability of DLC coated microdies were discussed.

\section{Development of in-situ observation system}

The developed in-situ observation system consists of; (a) a high-precision desktop-size servo screw press machine, DT-J312, Microfabrication Llc. with a work material feeder for progressive process, (b) a developed micro-bending die assembly with transparent observation window, (c) a high-speed camera unit, and (d) a triaxial high-precision stage for the adjustment of focusing in the observation by this high-speed camera. The main requirement for designing the micro-bending die assembly targeting for the in-situ observation system is as follows:

1. Realization of the severe contact state under progressive micro sheet metal forming,

2. Equipment with the observation window at the contact area during forming,

3. Observation with the high-resolution image for dynamic variation of the contact states.

The appearance of the developed system and schematic illustrations of the micro-bending die assembly are shown in Fig. 1. Coil of the foil strips are placed in the material feeder, and fed foils into the die assembly are firstly blanked with the blanking die set in the progressive die and it is continuously fed to the bending part. The width and length of the blanked specimen are $3 \mathrm{~mm}$ and $14.6 \mathrm{~mm}$, respectively.

At the bending stage, the blanked specimen are bent with the micro-bending punch with corner radius of $0.5 \mathrm{~mm}$ and width of $5 \mathrm{~mm}$, and with the bending die with the radius of $0.5 \mathrm{~mm}$. In order to observe the contact interface between the die and work materials during the micro-bending, one of these bending dies was made of fused silica glass with high transparency. In the developed observation system, the area of $3 \mathrm{~mm} \times 4 \mathrm{~mm}$ below the end of corner radius was chosen to observe the ironing contact state after bending. The contact state was sequentially recorded by high-speed camera observed from back side of the bending die made by fused silica glass. With the equipped observation lens, it is possible to record the variation of the contact state at interface through this transparent bending die with 750 times magnification.

\section{In-situ observation in progressive micro-bending process}

\subsection{Set up for progressive micro-bending tests}

To verify the availability of the developed in-situ observation system, the delamination behaviour of the coated DLC films during the progressive micro-bending process was observed. The material used was the thin-rolled stainless steel foils (JIS: SUS304) with the initial thickness of $t_{0}=50 \mu \mathrm{m}$. The depositions of DLC films on the micro-bending die made by fused silica glass, as shown in Fig. 3, were 


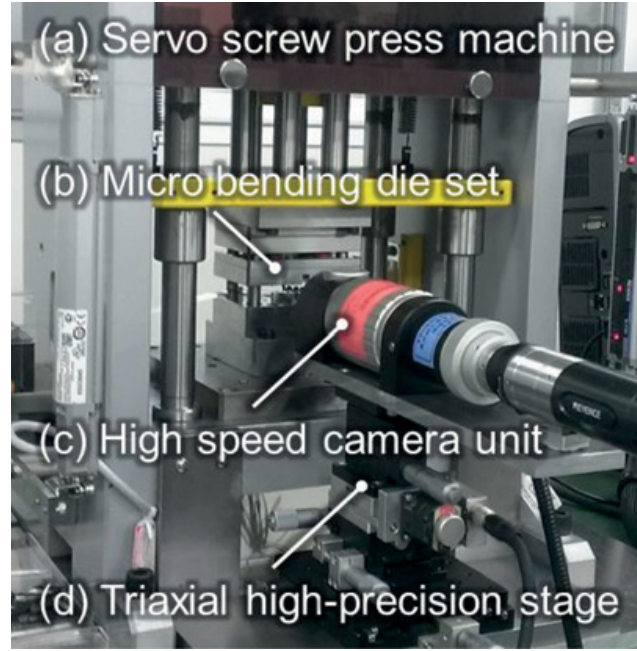

(a) Appearance of the developed system

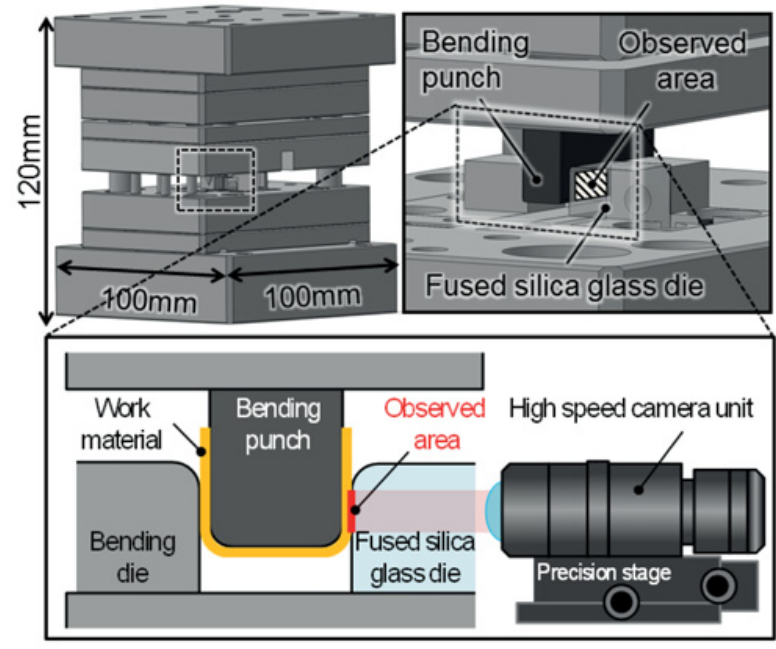

(b)Schematic illustration of micro-bending die assembly

Figure 1. Designed drawings of developed in-situ observation die.

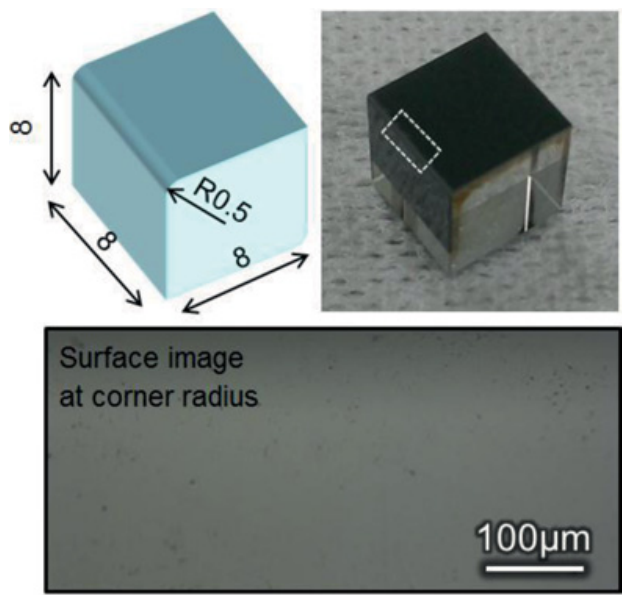

Figure 2. Dimension, appearance and its surface image of DLC coated micro-bending die.

performed in an ionized-physical vapour deposition system (NPS-330S from Nanotec Corp.) with a usable coating volume of $\phi 150 \mathrm{~mm} \times 150 \mathrm{~mm}$. In this system, the direct current ion source, composed with a tantalum (Ta) filament and anode electrodes, was installed to ionize the $\mathrm{C}_{6} \mathrm{H}_{6}$ benzene gas for the deposition. In order to improve the adhesion strength to the silica glass, silicon carbide, SiC, films were deposited as interlayer. The conditions of whole process above are summarized in Table 1 . The dynamic variation of the contact state at interlayer between the transparent die and work materials were continuously recorded by the equipped high speed camera as mentioned above. 


\section{MATEC Web of Conferences}

Table 1. Deposition conditions of DLC on transparent micro-bending die.

\begin{tabular}{ll}
\hline Pre-treatment of substrate & $\begin{array}{l}\mathrm{Ar}^{+} \text {bombard } \\
\mathrm{dc}-1.5 \mathrm{kV} \text { for } 30 \mathrm{~min}\end{array}$ \\
\hline Gas species & $\mathrm{C}_{6} \mathrm{H}_{6}$ \\
Gas Flow Rate $(\mathrm{sccm})$ & 1.5 \\
Gas Pressure $(\mathrm{Pa})$ & $2.2 \times 10^{-1}$ \\
Bias Voltage $(\mathrm{kV})$ & -1.0 \\
Filament Current $(\mathrm{A})$ & 30 \\
Anode Current $(\mathrm{A})$ & 0.4 \\
Temperature $\left({ }^{\circ} \mathrm{C}\right)$ & 250 \\
Deposition time $(\mathrm{h})$ & 4.5 \\
\hline
\end{tabular}

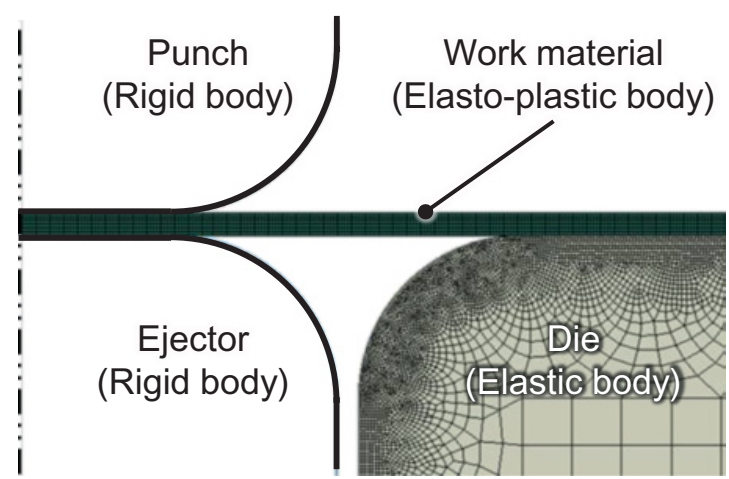

Figure 3. Schematic illustration of FE model of micro-bending test.

Table 2. Input mechanical properties of work materials and bending die.

\begin{tabular}{c|c|c}
\hline & Work material & Die \\
\hline Material model & Elastic-plastic body & Elastic body \\
\hline Mass density [g/cm $\left.{ }^{3}\right]$ & 4.51 & 14.6 \\
\hline Young's modulus [Gpa] & 106 & 610 \\
\hline Yield stress [MPa] & $510 \mathrm{MPa}$ & - \\
\hline Poisson's ration & 0.34 & 0.27 \\
\hline
\end{tabular}

\subsection{Finite element (FE) analysis of contact state}

To discuss the contact state under micro-bending tests, the contact length and local surface pressure is the most important parameter. Since the micro-bending die assembly is relatively small, it is difficult to install the load sensors to measure the actual contact length and surface pressure during the process. Thus, in order to identify the actual contact length and surface pressure, the FE analysis was carried out. Simulation was carried out with an explicit dynamic finite element code, ABAQUS ver.6.13/ Explicit. A schematic illustration of the model is shown in Fig. 3. The foil material was modelled with a quadrilateral 4-node bilinear element with the size of $5 \mu \mathrm{m} \times 5 \mu \mathrm{m}$, and was assumed as an isotropic elasto-plastic body. The material properties, which was used in the analysis was summarized in Table 2. The microbending die was modelled as elastic body and punch and the ejector of the work material were assumed as rigid bodies. For the contact conditions, the friction coefficients between the work materials and the tools were assumed to be 0.1 . The modelled mechanical properties are summarized in Table 2 . 

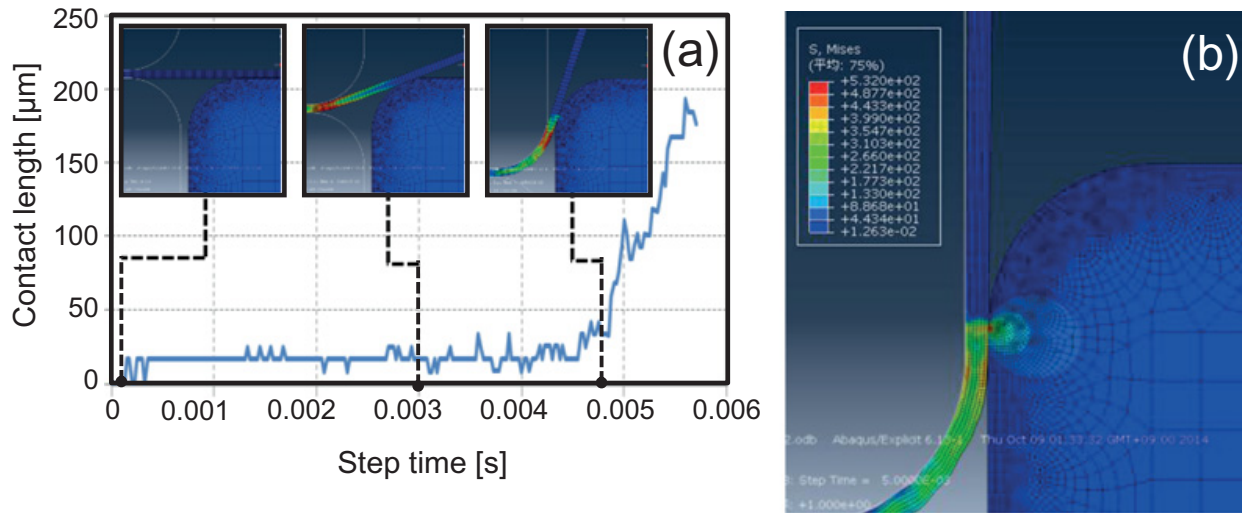

Figure 4. FE simulation of contact state in micro-bending process, (a) variation of contact length, (b) contour figure of von Mises stress applied on the die and the work material.

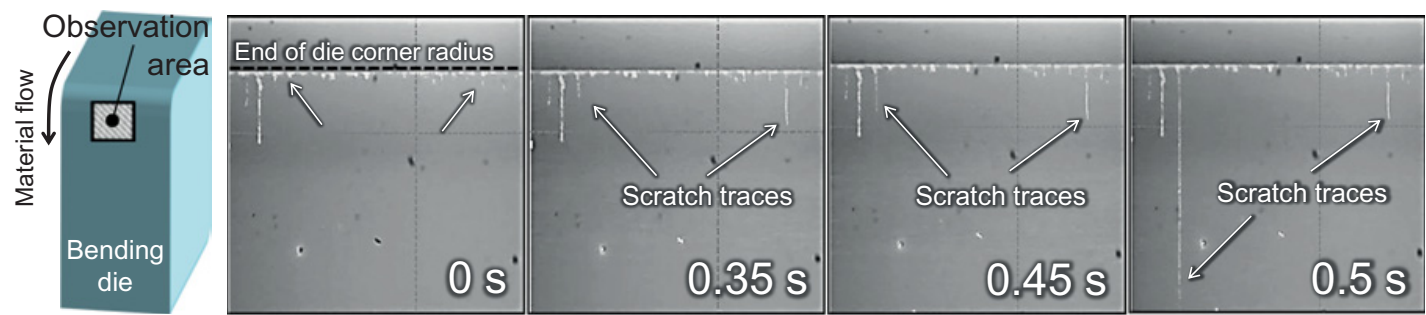

Figure 5. Dynamic variation of the scratch traces on DLC films deposited on micro-bending die, observed by developed in-situ observation system.

\section{Results and discussion}

\subsection{Contact state under micro-bending test}

Figure 4 summarizes the variations of calculated contact length during the micro bending process. In addition, contour figure beside the graph indicates the distribution of surface pressure on the bending die. As can be seen from the graphs, the contact length generally increases with increasing of the punch stroke and rapidly increases when the blank was drawn into the end corner of the bending die radius. Within this calculation, the contact state at the observation area as shown in Fig. 1 is found to be with a contact length of $120 \mu \mathrm{m}$ and with a maximum surface pressure of $530 \mathrm{MPa}$.

\subsection{In-situ observation of contact state of DLC fiilm}

Under the contact state as revealed above, the progressive micro-bending tests were carried out. Figure 5 shows the obtained images at the process number of 10th. Each image was obtained at each sequential motion of $0 \mathrm{~s}, 0.35 \mathrm{~s}, 0.45 \mathrm{~s}$, and $0.5 \mathrm{~s}$ after the punch stroke was started. As can be clearly seen from these dynamic sequential images, the scratch traces at the DLC films were developed with punch stroke. This suggests that the films were partially delaminated due to the abrasion by some hard particle or wear debris during the sliding of the work material. In particular, it can be confirmed that this delamination was originally started from the end of the corner radius, which might have the highest surface pressure. Therefore, it can be assumed that the ploughing behaviour might be a main factor to originate the delamination of the DLC films. 


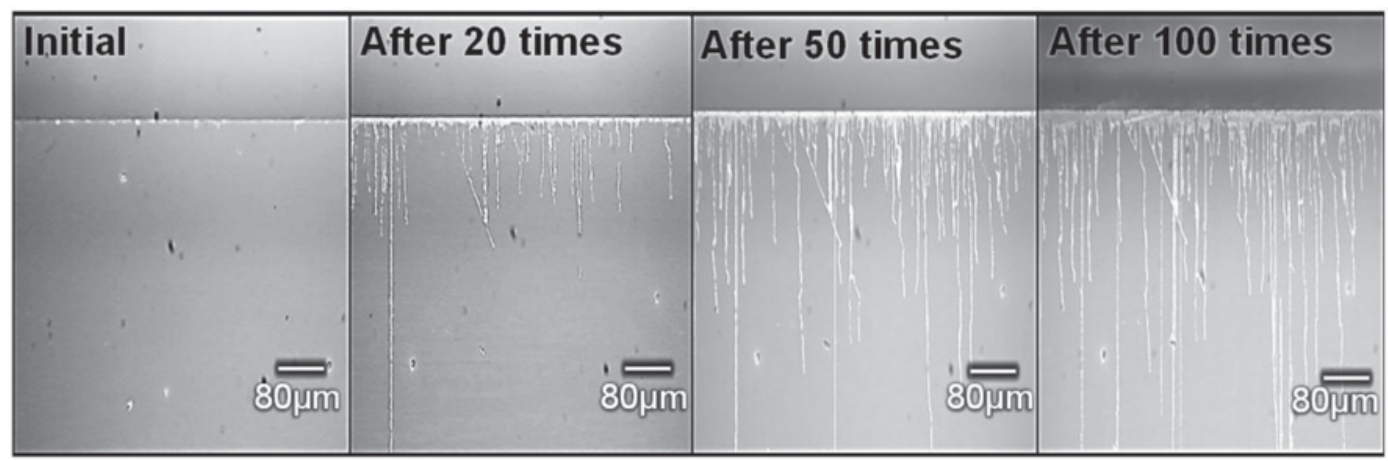

Figure 6. Progressive evolution of the delamination behaviour of DLC films deposited on micro-bending die, observed by developed in-situ observation system.

Additional observations were carried out until the process number \#100. Figure 6 shows this evolution at the initial state and after the process \#20,\#50, and \#100. The traces of the scratches increase with increasing number of the process. These delaminated areas might promote the adhesion of the work material on the die and it might worse the tribological state during the forming process. Consequently, by using the developed in-situ observation system, the dynamic and progressive variation of the contact state under the actual forming process was successfully demonstrated.

\section{Conclusion}

In the present study, to observe the dynamic variation of the contact state during the microforming operation, a novel microforming die assembly with the in-situ observation system with silica glass die and high speed recording camera was developed. By using this system, the dynamic and progressive delamination behaviour of DLC films during the progressive micro-bending process was successfully demonstrated. Under the contact condition with the contact length of $120 \mu \mathrm{m}$ and with the apparent surface pressure of $120 \mathrm{MPa}$, the delamination was originally started at the end of the corner radius of bending die. From the obtained image, this delamination might be attributed to the ploughing behaviour with hard particles or wear debris from the work materials. Further development of DLC films appropriate for the microforming operation will be investigated in the future based on this image analysis.

\section{References}

[1] U. Engel, Wear, 260, 265 (2006)

[2] T. Shimizu, H. Komiya, T. Watanabe, Y. Teranishi, H. Nagasaka, K. Morikawa, M. Yang, Surf. Coat. Technol. 250, 44 (2014)

[3] A. Grill, Surf. Coat. Technol. 94-95, 507 (1997)

[4] X.D. Yang, T. Saito, Y. Nakamura, Y. Kondo, N. Ohtake, Diam. Relat. Mater. 13, 1984 (2004)

[5] N. Krishnan, J. Cao, K. Dohda, ASME J. Manuf. Sci. Eng. 129, 669 (2007)

[6] K. Fujimoto, M. Yang, M. Hotta, H. Koyama, S. Nakano, K. Morikawa, J. Cairney, J. Mater. Process. Technol. 177, 639 (2006)

[7] T. Aizawa, K. Itoh, E. Iwamura, Steel Res. Int. 81, 1169 (2010)

[8] Z. Hu, A. Schubnov, F. Vollertsen, J. Mater. Process. Technol. 212, 647 (2012)

[9] C. Wang, B. Guo, D. Shan, X. Bai, J. Mater. Process. Technol. 213, 323 (2013)

[10] Y. Aoki, N. Ohtake, Tribol. Int. 37, 941 (2004) 